\title{
Crafts and Technologies of the Chalcolithic People of South Asia: An Overview
}

\author{
Vasant Shinde and Shweta Sinha Deshpande*
}

(Received 15 January 2015)

\begin{abstract}
The Chalcolithic or the Early Farming community flourished from 7000 BC to first millennium BC all over South Asia due to many factors, including climate change and population pressure. A large number of sites discovered and selected ones excavated have thrown flood of light on various aspects of their lifestyle, including crafts and technological advances made by these people. Most of the technologies were innovated due to sheer necessities. This paper discusses the evidence from excavated sites a variety of pyro and non-pyro technologies the Chalcolithic people introduced and used over such a long period.
\end{abstract}

Key words: Ahar culture, Chalcolithic, Chalcolithic technology, Deccan, Jorwe culture, Kayatha culture, Northwest India, South Asia.

\section{INTRODUCTION}

Technology forms the most important aspect of any culture, as it is the gauge for assessing economic and social developments within human society during its various phases of history. It is the systematic study of techniques (craft) for making and doing things; and is concerned with the fabrication and use of artefacts. It has been defined as the application of scientific knowledge to the practical aims of human life or can also be described as the change and manipulation of the human environment and thus is a social phenomenon that cannot be disassociated from the society in which it exists. It has been suggested that 'necessity is the mother of all inventions' and to some extent this has been projected through the various phases of history.

The introduction of technological aspects can be seen right from the introduction of a stone tool in the Lower Palaeolithic times around three million years ago and since then there has been a steady growth and gradual induction of complex technologies from time to time. The rate of technological change that took place until the introduction of farming (the period of the Early Farming communities is usually referred to as either Neolithic in some regions or Chalcolithic in other) was slow and spread over a long period of time and was in response to only the most basic human needs; the search for food and shelter. The dates for the beginning of Early Farming communities differ from region to region. The Levant region, one of the most fertile regions of the world in West Asia is evidently considered to have witnessed the gradual process from HuntingGathering to incipient agriculture sometime towards the end of Pleistocene period and the beginning of the Holocene period around 12000 to 15000 years ago. The various technologies that were developed there began to spread in all directions within the neighbouring and far off regions and are believed to have come to the north-

\footnotetext{
* Department of Archaeology, Deccan College Post-Graduate and Research Institute, Deemed University, Pune, India. Email: vasant.shinde@dcpune.ac.in
} 
western part of the subcontinent through the Bolan pass around $7000 \mathrm{BC}$.

In the context of South Asia, till the beginning of the twentieth century when the systematic research on Protohistoric cultures began, most historians were of the opinion that settled life began in the Early Historic period around the $6^{\text {th }}$ or $5^{\text {th }}$ century BC with the period between the Stone Age and the Early Historic period considered to be a "Dark Age". However, the discovery of the Harappan Civilization in the 1920's and Chalcolithic in the 1950's pushed back the antiquity of settled life in the sub-continent by two thousand years at one stroke. This is considered to be the greatest archaeological discovery in South Asia of the twentieth century. The development and spread of agriculture and pastoralism in South Asia are complex phenomena that have taken place over the course of more than 9000 years with the technological breakthroughs in pottery, metalworking, bead manufacturing, monumental architecture, etc.

\section{EARly FARming Communities of South Asia}

The Indian subcontinent has all the favourable ecological conditions necessary to give rise to the early farming communities, referred to as Neolithic or Chalcolithic. The region witnessed two independent streams of origin of village economies with the associated technologies, which evolve and develop through the early phases of village societies into the developed and mature complex villages and the early cities hence it is important to trace the ongoing cultural process in the region. On the basis of material culture and technologies in use, the Chalcolithic of South Asia has been sub-divided into Early, Mature and Late phases. The earlier beginnings (approximately around $7000 \mathrm{BC}$ ) are seen in the northwest regions of Afghanistan and Baluchistan, possibly as a result of the influence coming from Southwest Asia. Similar development slightly later in date was witnessed in parts of western India, southeast Rajasthan in the Banas River basin and the MidGanga regions. In the rest of India the development of village-based culture started in the later part of the Mesolithic phase and continued into the Neolithic and Chalcolithic between 3500 and 1000 BC. The declined phase of the Chalcolithic has been properly studied at the site of Inamgaon in the Bhima basin of the lower Deccan region. Of the early farming communities that came into existence in different parts of South Asia, the Chalcolithic phases in Central India, the Deccan and the South India have been systematically studied, thanks to the pioneering work by Deccan College under the leadership of H.D. Sankalia. Unfortunately, the eastern and north-eastern parts of the country have not been subjected to systematic archaeological research and therefore very little is known about these regions.

The large numbers of Chalcolithic cultures identified in the subcontinent have been classified into ten regional traditions:

i. Baluchistan and adjoining regions (beginning from $5^{\text {th }}$ millennium BC)

ii. Padri and Prabhas Patan traditions of Saurashtra ( $4^{\text {th }}$ millennium BC)

iii. Anarta tradition of North Gujarat ( $4^{\text {th }}$ millennium BC)

iv. Ganeshwar-Jodhpura of Northwest and western Rajasthan ( $4^{\text {th }}$ millennium BC)

v. Ahar tradition of Mewar ( $4^{\text {th }}$ millennium BC)

vi. Kayatha and Malwa traditions of the Malwa Plateau ( $3^{\text {rd }}$ millennium BC)

vii. Savalda and Jorwe traditions of the northern Deccan ( $3^{\text {rd }}$ millennium BC)

viii. Neolithic/Chalcolithic traditions of eastern India including Mid Ganga region ( $4^{\text {th }}$ millennium BC)

ix. Ochre Colour Pottery/Copper Hoard tradition of North India ( ${ }^{\text {rd }}$ millennium BC) 
x. Narahan culture of eastern Uttar Pradesh (towards the end of $2^{\text {nd }}$ millennium BC)

Each of these is characterised by similar features with agro-pastoral economy, trade, social, political and economic stratification with minute differences in style of pottery manufacture and the level of technological development and the origin and evolution of these techniques, which will be discussed in the forthcoming paragraphs.

The earliest evidence of agriculture and pastoralism in South Asia comes from the site of Mehrgarh situated on the north Kachhi plain at the foot of the Bolan Pass (Jarrige, 1984). The region includes the Kachhi plain at the mouth of Bolan pass, the Quetta valley, the Khozdar area in the Kalat plateau, the Kotwa region, the Bela area, the coastal plain of Sonmiani Bay and the Turbat oasis. It is a buffer zone between the Iranian Plateau and the Indus Basin and therefore significant from the point of the development of early village cultures which could have moved west from the Iranian plateau as a result of agricultural viability. Barley-wheat cultivation and cattle and sheep/goat domestication, similar to that of West Asia, dominated the economy and hence the foreign influence for the first villages within the subcontinent (particularly in the north-western) probably cannot be denied. The most impressive evidence of this early occupation was unearthed at the site of Mehrgarh between 1974 and 1985 (Jarrige, 1984; Jarrige et al., 1995). The Aceramic Neolithic farmers first occupied the site around 7000 BC, while the subsequent phases of the Neolithic and Chalcolithic show a continuation and gradual development in the material culture, culminating to form the Early Harappan phase (3000 BC). The early phase at Mehrgarh is characterised by the presence of a well-developed lithic (flint) industry, circular to rectangular structures some of which were made of loafshaped mudbricks, terracotta female figurines and human burials. Pottery appears first in the
Neolithic around $6500 \mathrm{BC}$ and copper during the Chalcolithic around 4500 BC. A number of local pre-Harappan Chalcolithic cultures such as the Hakra, Kot Diji, Amri, Nal and Ahar follow and all of them have contributed substantially to the development of the Harappan Civilization.

The regions of Mewar and the Mid Ganga basin appear to have witnessed the process of domestication and formation of village life independently in the $6^{\text {th }}$ millennium BC (Shinde et al., 2004 and Tiwari, 2002-03). The Mesolithic site of Bagor in Mewar has produced evidence of early animal domestication and semi-permanent sedentary occupation (plant remains were not recovered and studied from this site) from where begins the origin of a complex village organisation that spread into various parts of Rajasthan and Gujarat (Shinde, 2000; 2002 and Shinde et al., 2004). The site of Lahuradeva in the Mid Ganga basin has also provided similar kind of evidence (Tiwari, 2002-03). The works at the site of Padri (Saurashtra), Nageshwar and Loteshwar (North Gujarat) and Balathal and Gilund in the Mewar region of Rajasthan have provided evidence of early village life going back to the middle of $4^{\text {th }}$ millennium BC (Shinde, 1998; Sonawane and Ajithprasad, 1994).

The early phase is characterised by small but growing complex communities which have already realized the favourable factors of a sedentary lifestyle along with a mixed economy based on agriculture, animal husbandry and some amount of hunting, gathering and fishing wherever possible. The basic technological breakthrough in ceramic, smelting and melting of metals and artefact manufacture in the form of tools, utensils, ornaments, construction techniques, etc. has seen its origin and initial evolution in this early phase of socio-economic complexity. These are the technologies developed and introduced gradually by the Neolithic/Chalcolithic folks within the subcontinent. 
The developed (mature) Chalcolithic phase is marked by the presence of specialized craft production, use of advanced technologies, a class-structured society, and economic prosperity reflected in their material culture and the establishment of long distance trade networks. It is in this developed phase that one can see an overall development in pyro- and non-pyro technologies. Excavations carried out at sites like Inamgaon, Daimabad in the Deccan, Navdatoli, Eran and Nagda in Central India, Balathal, Gilund, Ojiyana in Mewar, Ganeshwar, Jodhpura in Western Rajasthan and Lehuradeva in the Mid Ganga plain, and a number of Copper Hoard culture sites in north India have thrown a flood of light on the various technologies in use during this period and these sites have also produced positive evidence in respect to the presence of a craft specialization. Convincing evidence in relation to the presence of a chiefdom society has been documented at a number of sites including Balathal (Sinha, 1998), Gilund and Inamgaon (Dhavalikar et al., 1988; Shinde, 1991), while evidence of religious beliefs including fire worship, male and female terracotta figurines, bull figurines and burial of the dead has been documented at a number of Chalcolithic sites in the Deccan (Dhavalikar, 1998).

In general the Neolithic/Chalcolithic phase in the Indian subcontinent was characterized by sedentary settlements, domesticated plants and animals, a ground and chipped stone industry with a microlithic component, restricted use of copper technology, hand-made and wheel-made plain and painted pottery and also Black-and-Red ware, a mixed subsistence based on farming, stock raising and limited hunting and gathering (Agrawal and Kharakwal, 2003). A number of Chalcolithic cultural sub-traditions have been identified and though most of these share a number of common features, they produced distinct painted pottery allowing differentiation. Most of the sites in the region under study seem to be first occupied in the developed Chalcolithic phase dated between
$2500 \mathrm{BC}$ and $1000 \mathrm{BC}$, the most prosperous phase of the Chalcolithic culture. The excavation work carried out at a number of sites in central and south India suggests that origins of the village life took place at few selected sites and subsequently, after they attained prosperity and their population increased they spread over the remaining subcontinent. Evidence from Mewar indicates that the developed Chalcolithic phase in this region ultimately culminated in proto-urbanization, which was parallel and contemporary to the Harappans but independent of it. In order to acquire required raw material and finished goods they developed contacts with different regions and had strong trading contacts with the Harappan Civilization.

By 1500/1000 BC most of the Chalcolithic settlements from the Indian subcontinent were deserted and only a few sites managed to survive until 700 BC in the southern Deccan region, particularly the Bhima River basin where the important site of Inamgaon is located (Shinde, 1989). The data from the Late Chalcolithic phase from all over clearly indicates decline in the material and technological culture implying degradation in lifestyle. Circular huts replace the large spacious houses of the earlier phase and the classical Chalcolithic painted pottery degenerates in quality. The dependence of the people on agriculture for their subsistence changes to a more semi-nomadic mode with increased dependence on sheep/goat pastoralism. The reason for this decline is not yet properly understood, but the onset of arid climatic conditions may have been responsible.

\section{Chalcolithic Crafts and Technologies}

The introduction of various technologies is considered to be one of the important contributions of the Chalcolithic phase and these techniques can be divided into two broad categories; pyro and non-pyro, which have been described briefly. 


\subsection{Pyro Techcnology}

It includes industries that involve the use of fire during the manufacturing process. There is ample evidence in the Chalcolithic levels for the use of pyro-technoloies (pottery, bricks, terracotta, lime, paste and faience, metallurgy including copper and gold/silver, etc.).

\subsubsection{Pottery Manufacture}

The earliest evidence of pottery manufacture comes from the site of Mehrgarh in Baluchistan, dated to 6500 BC. One of the characteristic features of the Chalcolithic period is a well-developed ceramic industry. They produced fine painted and plain and coarse pottery for a variety of purposes. Besides, the people of the Ahar and Narahan cultures also produced Black-and-Red wares. Pottery manufacture was an important craft of the Chalcolithic period and all the three techniques- handmade, slow turned table and fast wheel were in use simultaneously. The fine pottery was made from fine and pure well levigated clay whereas to produce the coarse variety, tempering materials such as fine sand, chopped grass, rice husk, cow or donkey dung, etc. were mixed in the fine clay. Invariably the fine ware was treated with various shades of red colour slip over which were executed painted decorations in black or other dark colours and then fired at $750^{\circ} \mathrm{C}$. All the colours were prepared of the naturally occurring haematite rock. Usually the fine wares were fired in closed kilns with long fire chambers at the base, the evidence of which is found at sites like Inamgaon (Dhavalikar et al., 1988), Kaothe (Dhavalikar et al., 1990), Balathal (Shinde, 2000), etc. The Black-and-Red ware was possibly fired in closed kilns, but possibly the pots were kept in up-side-down (called the inverted firing technique) in the kilns for firing, different from the one used for firing other wares. Various geometric and naturalistic patterns were decorated on the upper half of the outer surface of the pottery. In case of wide mouthed pots such as bowls, they were executed on the inner surface too. The most common shapes include bowls, lotas, carinated wide mouthed spouted pots and small to medium globular pots. Small to medium sized globular pots were used for cooking, whereas large sized ones for storage purposes. A number of sites have produced evidence of pottery manufacture and one of the best examples of a pottery workshop was reported from the site of Inamgaon. It included terracotta and stone dabbers, antler and bone points, pounders, fragments of haematite for preparing colour, pebbles probably for burnishing, and specifically designed circular kilns with long fire chambers. A number of sites including Balathal and Gilund in Mewar, Kaothe in the northern Deccan, Navdatoli in central India, etc. have produced convincing evidence of pottery manufacture. A study of site catchment analysis of selected sites clearly demonstrates that the locally available clay, mainly from riverbeds was used for pottery making (Dasgupta, 2004). Since most of the potters still use technology that is similar to the Chalcolithic, the study of the modern pottery technique including clay preparation, shaping of pots, surface treatment and decorative patterns, firing techniques and post-firing decorations, etc. will enable reconstruction of the Chalcolithic pottery manufacture technology in the subcontinent.

\subsubsection{Burnt Brick}

The earliest evidence of the use of burnt brick for construction comes from the site of Gilund, dated to the beginning of $4^{\text {th }}$ millennium $\mathrm{BC}$, which was excavated by the authors. It should be mentioned that this building material was not common in the Chalcolithic period in South Asia. Occasional use of such bricks for construction is attested at sites like Nagda and Eran, where it was used for the construction of fortification wall. At Gilund most of the structures on the southern part, identified as a craft manufacture area of the mound two (GLD-2) have been made of burnt bricks. The 
Chalcolithic people at Gilund also introduced the header and stretcher construction method. Bricks are usually made away from the habitation site and therefore there may not be any trace of their manufacture within the site. Similar burnt bricks are being manufactured in the rural parts of India by using the same technique as that of the Chalcolithic. A study of the modern brick manufacture and firing technique will help in the reconstruction of the one in use during the Chalcolithic times.

\subsubsection{Terracotta}

In the subcontinent from the very beginning terracotta art is associated with settled life. A large number of terracotta objects were manufactured and used by the Chalcolithic people including those of domestic and religious use. The domestic ones include spoons, ladles, ornaments such as beads, bangles, ear-studs, etc. A number of sites have yielded animal figurines such as the bull, tortoise, a variety of birds, human (male and female) and a variety of miscellaneous objects, most of which have been associated with the religious beliefs of the people. Potters most probably manufactured these objects locally. These objects were hand-modelled, made of fine clay, sometimes treated with either red or grey slip and fired to a temperature of around $650^{\circ} \mathrm{C}$. Sites like Kayatha and Marmi in central India, where large number of bull figurines was found, appear to be centres of production (Misra et al., 1993). Inamgaon has yielded a large number of terracotta figurines, including male and female and it will not be far fetched to surmise that it was one of the important regional centres of the manufacture of these figurines. Most of the sites producing the evidence of pottery manufacture will be ideal ones to study for the terracotta manufacturing techniques. As before, there are ample ethnographic parallels in modern western and eastern parts of the country where such techniques can be studied.

\subsubsection{Lime}

Chalcolithic house floors, walls and sides and bottoms of silos were plastered with lime, mainly to keep away insects. This indicates its manufacture and use by the Chalcolithic people. Although there is an evidence of the use of lime at almost every excavated Chalcolithic site, the only site that has produced the evidence of manufacture is Inamgaon, where lime making was a flourishing industry in the Jorwe levels. Calcified grit (kankar), which abounds in Maharashtra, was used in the process and a limekiln constructed of undressed stones was found along with large quantities of lime balls (Dhavlikar et al., 1988). The reconstruction of the lime making technique will have to be done by undertaking experimental works.

\subsubsection{Paste and Faience}

Right from the beginning of the Chalcolithic phase, as is evident at sites like Mehrgarh, Padri, Prabhas Patan, Balathal, Gilund, etc., paste and faience beads formed an important part of their jewellery. It appears that the paste beads were made from the white quartz powder in which was added alumina, sodium and potassium as flux. Faience is made from ground quartz sintered with glassy bonding material made with alkalis and lime and glazed with bright coloured alkaline and lime glazes containing metal oxides. Both were then fired in small kilns. Kilns for firing paste beads have not been identified at any Chalcolithic site. Also there is a need to identify workshops and tools used in the manufacture of this craft. This craft has not been properly studied and understood and therefore we have not yet understood various aspects such as the exact nature and source of raw materials, manufacturing process, firing techniques, etc. The Harappan site of Kuntasi in Saurashtra, Gujarat, contemporary to the Chalcolithic period has produced a large, circular fireplace, which is identified as a paste-bead firing kiln (Shinde, 
2004). A large circular kiln, built in a pit and provided with a thick layer of sand all around, called sand bath, contains a large pot, which may have been used as a container for the beads to be fired. The Chalcolithic craftsmen may have used a similar kind of kiln for firing purposes.

\subsubsection{Copper Metallurgy}

The technological development of copper metallurgy in the subcontinent has been well documented (Agrawal, 1971 and 2000). Chalcolithic people were responsible for the origin and development of this metallurgy, the evidence for which is found right from the middle of fifth millennium BC. The source of Khetri Copper belt of Rajasthan may have provided the required raw material to the people of the Chalcolithic and even subsequent cultures. This is the richest source of copper available in South Asia even today. In addition, other locally available chalcopyrite nodules may also have been exploited for this metal. The smelting activity was apparently done away from settlements, as the discovery of sites yielding massive deposits of copper slag near the source of copper in Rajasthan would indicate. As these sites have not been subjected to systematic research, the data on the mining of copper ore and the techniques of extraction of metal is not available. There is a possibility of the use of antler picks, the evidence of which is found at a number of Chalcolithic sites in Rajasthan and Central India, for mining the ore of copper from the mines. A number of tribal communities in Central India are engaged in the mining and smelting of copper ore and manufacture of objects by using primitive technique, which is believed to be similar to the one used during the Chalcolithic period. A study and documentation of their primitive techniques will enable reconstruction of technological features of the Chalcolithic period.

Extracted metal was transported to the habitation sites where it was converted either by casting in mould or cold hammer techniques evident at most of the sites into various artefacts, including tools and ornaments. Copper objects recovered from the site of Kayatha in central India were found to be made by the use of casting technology (Ansari and Dhavalikar, 1974), whereas those found at all other Chalcolithic sites were made by cold hammering technique. Various tool types found at numerous excavated sites include flat axes, spearheads, swords, arrowheads, chisels, points, punches, nails, etc. and ornaments such as beads, pendants, bangles, rings, etc. Some of the Chalcolithic communities close to the source of Khetri, particularly Ganeshwar-Jodhpura were fully engaged in the manufacture of various copper objects for their consumption as well as for trade purposes. They, in all probability, supplied copper ingots and copper objects to the Harappans as well as to the Chalcolithic people of other traditions. It seems some tools such as leaf-shaped arrowheads, chisels and nails were made here for the Harappans. In the Gangetic basin and parts of the northern Rajasthan large number of heavy copper implements such as anthropomorphs, harpoons, swords, etc. have been reported from a number of sites. They have been associated with the Copper Hoard/OCP culture dated to the beginning of second millennium BC. Their function and manufacture technique is not known. Was there the use of the lost wax technique for making these objects like the ones used by the tribals of Bastar in M.P.? Detailed observation on this aspect is required. Sites like Ahar and Balathal in the Mewar, Inamgaon and Daimabad in the Deccan, Padri in Gujarat, Ganeshwar and Jodhapura in Rajasthan have evidence of copper object manufacture as crucibles and small furnaces for heating and melting this metal are present. The site of Kayatha in central India need to be studied for getting full insight into the complex copper object manufacture technology. Chalcolithic copper objects and the samples of the modern copper ore will have to be subjected to X-Ray diffraction, chemical and neutron activation analysis to study the source region of the raw 
materials. Besides, some of the tribals of Bastar region still practice primitive technology, and need to be subjected to detailed studies with a view to generating data on reconstructing Chalcolithic manufacture technology. At the site of Ahar in Mewar, iron was recorded in the Chalcolithic level dated to $1400 \mathrm{BC}$. This is the most significant evidence, which will enable understanding of the origins of iron technology in the subcontinent. It is not unlikely that the copper technology developed by the Chalcolithic people served as the basis for the development of iron technology. The site of Ahar will have to be studied in great details from this point of view.

\subsubsection{Gold}

Small number of gold ornaments have been reported from selected excavated sites. They include mostly beads and pendants, which were made by foil technique. In all probability the Chalcolithic people acquired gold from Hatti mines near Gulbarga in Karnataka. There appears to be possibility of spacer gold being exploited in other regions. A small circular furnace in one of the structures at Inamgaon as well as a pair of tongs, as opined by the excavators, may have been connected with gold ornament manufacture activity (Dhavalikar et al., 1988). Efforts will be made to highlight on the aspects such as the source of gold, technique of mining, technique of manufacturing, etc. in this book. No convincing evidence of the use and manufacture of silver objects in the Chalcolithic levels has been encountered in the subcontinent.

\subsection{Non-Pyro technology}

As can be understood, it deals with manufacturing techniques without the use of fire and includes the following:

\subsubsection{Architecture}

The Chalcolithic period in general is characterised by simple to complex structures of mud, wattle and daub, stones, mudbricks or burnt bricks. In addition, multi-room complexes, public architecture and well-planned settlements were also built. Architecture of different categories such as dwellings for common and elite classes, workshops for various craft manufacture, and public buildings such as fortifications, granaries, irrigation canals, jetties, religious structures, etc., have been identified at a number of excavated Chalcolithic sites.

The simple dwelling structures included subterranean or over ground circular huts and single or double-room squarish and rectangular units. These structures had low mud walls and wattle-and-daub construction over them (Sankalia, 1974). Most of the structures had well made plastered floors and walls, while inside cooking and storage areas are often found. There is no direct evidence for the manufacture of these architectural features in the archaeological context. Similar types of structures are being built till today and a study of these structures have yielded ample information about their construction method (Shinde, 1991a). Building and plastering of floor and walls also can be reconstructed by observing modern construction methods.

The structural complexes excavated at a number of sites, including Mehrgarh, Balathal and Gilund were made of mudbricks or stone, depending upon the availability of raw material in the vicinity of each site. These complexes had stone foundations and mudbrick walls over them. Some of the complexes excavated have over a dozen rooms of different sizes, and on the basis of contents it was noticed that each room of the complex served different function including dwelling, storage, craft manufacture, cooking, etc. In addition, multi-room complexes, public architecture such as fortifications and granaries and well-planned settlements are also found. The site of Balathal had a stone fortification wall, whereas Gilund, Eran and Nagda had mudbrick fortification walls around them. Mud walls 
fortified Inamgaon and Daimabad. The stones and mud bricks were set in mud mortar, whereas the mud walls contained stones at places for strengthening purposes. These walls, broad at the base and narrow towards the top, have survived to a considerable thickness. One of the aims of this paper will be to study their exact function and method of construction. A surrounding ditch also protected sites like Inamgaon and Nagda and this feature introduced by the Chalcolithic people, continued through the Early Historic into later periods in India. Granaries have been identified at Gilund and Inamgaon. The one found at Gilund is a large $15 \mathrm{~m} \mathrm{X} 12 \mathrm{~m}$ structure made of parallel walls of mud-bricks (Shinde and Possehl, 2005). Five parallel walls placed at a distance of $1.5 \mathrm{~m}$ from each other have been plastered from both, inner and outer faces. It is hypothesized that the place between the two walls was used for storage purposes. The structure identified as a granary at Inamgaon is a large squarish mud structure containing half a dozen circular platforms and same number of cylindrical underground pits (Dhavalikar et al., 1988). The top of the mud platforms and sides and bottoms of cylindrical pits (silo) were plastered with cow dung and lime. The platforms were used for supporting storage bins whereas the underground pits were used as storage containers. There are ethnographic parallels for both and hence it is not difficult to study their methods of construction and identify tools used for making them. A rectangular platform found by the side of the river Ghod close to Inamgaon has been identified as a jetty. The site of Balathal has produced unique evidence of a public structure identified as fortified enclosure. This roughly rectangular structure measuring $30 \mathrm{~m}$ (E-W) by $20 \mathrm{~m}(\mathrm{~N}-\mathrm{S})$ is the only structure of its kind in the Chalcolithic levels of South Asia (Shinde, 2000). It is located in the middle of the settlement with massive walls of stone set in mud mortar and bastions on two corners. The average thickness of the wall is $5 \mathrm{~m}$ on top and $7.5 \mathrm{~m}$ at the base.

\subsubsection{Flint-knapping}

One of the characteristic features of the Chalcolithic South Asia is the presence of a blade industry right from the beginning of this phase. The first author has conducted experiments on the blade tool manufacture method in Denmark and is in a position to write substantially on the blade tool manufacture technique. The fine slender and parallel-sided blades can be detached from the core by applying either the punch or pressure technique. The most common materials used by the Chalcolithic were chalcedony and chert, with occasional use of quartz and jasper. These are commonly found almost all over the subcontinent and possess concoidal fracture property, a basic requirement in the manufacture of blade tools. The raw stones are first dressed into desired form by removing flakes with a stone hammer and while preparing the core one or more ridges are created along the longitudinal axis. There are number of specimens showing parallel flutings which are the negative flake scares of the blades that were already struck off. These parallel-sided blades then were converted into various tool types such as blunted back, crescents, trapeze, points, etc. by retouching them. These blade tools were either used in bare hands or made into composite tools such as sickles. On the basis of the even distribution of debitage and blades at Navdatoli, it has been suggested that every household prepared its own tools (Sankalia et al., 1974). At the site of Inamgaon a house of a flint-knapper has been identified, which contained in it more than a hundred crescents and large number of debitage around a stone, which may have been used as an anvil (Dhavalikar et al., 1988). Tools such as hammer stones, fabricators, antler and copper punches, etc. found at many sites may have been used for making blade tools. The entire blade tool manufacture technique can be reconstructed by undertaking experimental study and considering the works of experiments carried out by various scholars world over. 


\subsubsection{Lapidary}

This was one of the most important industries in the Chalcolithic period in the subcontinent throughout the Chalcolithic phase. Beads of semi-precious stones like agate, carnelian, jasper, chert, steatite, serpentine and so were manufactured at a number of sites. The technique of manufacture of bead rough-outs was not very different from that of manufacturing core for blade tools. Similar types of tools were used in the manufacture. Some of the sites have also produced sand stone slabs with parallel groove marks identified as bead polishers. The grooves appear to have resulted from polishing the bead rough-outs. The raw materials required for bead making if not locally available were sometimes acquired from long distance via trade networks. In the Khambat region of Gujarat, stone bead industry is still important where modern as well as traditional methods have been employed. A number of scholars have studied these techniques and systematically documented them (Kenoyer et al., 1991). This source will be of great help in the reconstruction of the bead making technology.

\subsubsection{Polished stone tools}

Chalcolithic sites in the Deccan have produced a considerable number of polished stone tools. The most common material used is dolerite, which is found all over the Deccan region. The tools consist of axes and adzes and in both cases grinding and polishing obtained the cutting edge. Either the entire body or its part is polished. Large number of polished stone tools have been recovered from Inamgaon, but there is no evidence of manufacture at the site. The manufacture technique may be simple. In the first stage a pebble is converted into a rough-out, which was then polished on the rough stone. The reduction or manufacture sequence can be reconstructed by experimental studies.

\subsubsection{Agriculture}

The Chalcolithic people grew a variety of crops, including wheat, barley, rice, a variety of pulses and oil seeds in the fertile black cotton or alluvial soils surrounding most of their settlements. Plough cultivation is inferred in the Chalcolithic levels although there is no direct evidence for the implements. The possibility is that the hard wood of khair (Acaci catechu) may have been used for making ploughs, which may not be different from the Harappan plough found in the form of a model at the site of Banawali. It has been argued in favour of hoe-cum-plough agriculture, but the actual discovery of a ploughshare made of a shoulder bone of cattle at Walki (Pune District, Maharashtra) demonstrates that such ploughs may have been made (Shinde, 1991b). Besides, antler picks and perforated discs referred to as mace heads found at many sites may also have been used for digging purposes (Shinde, 1987). As many parts of rural India still use technology similar to that of the Chalcolithic it may not be difficult to reconstruct Chalcolithic agriculture technology and visualize the types of tools used.

\subsubsection{Hydraulics}

Wheat was grown in the Deccan region with the help of artificial irrigation systems, which was developed by the Chalcolithic people. The best evidence of this comes from the site of Inamgaon in the lower Deccan region. The evidence of irrigation canal, $240 \mathrm{~m}$ long and 2.5 $m$ wide and deep was discovered between mounds I-III and IV. Parallel to it was constructed an embankment wall of stones set in mud mortar. It was build with a view to preventing the canal from silting up (Dhavalikar et al., 1988). This is the best hydraulic evidence associated with the Chalcolithic in South Asia. The site has yielded a number of antler picks, which may have been used for digging this canal. Besides, a number of small rivers, particularly tributaries of major rivers, may have been dammed for irrigation purposes. We have no clue whether or not the Chalcolithic people dug wells and water tanks within the site. Reconstruction of canal digging and building of 
embankment is not difficult, as this practice continues in this region even now.

\subsubsection{Shell industry}

The Chalcolithic people for making bangles and beads used conch or chank shells. The nearest source for this variety of shell was Saurashtra and the Harappan trade networks distributed it. The outer surface of the shell was removed and then it was cut in a circular manner with the middle stem called columella thrown away. A number of sites have produced evidence in the form of finished and unfinished products indicating its local production. Copper knives and stone blade tools found at many excavated sites may have been employed for manufacture (cutting). Shell bangle manufacture is one of the flourishing industries in West Bengal, where modern and traditional technologies are employed. A study of traditional technique for making bangles may prove to be useful in the reconstruction of Chalcolithic technology.

\subsubsection{Bone/antler/wood}

Almost every Chalcolithic site has the evidence of bone and antler tools, indicating local production at almost every site, save temporary settlements such as farmsteads or camps. A few beads made of bone have also been reported. Bone and antler tools such as chisels, knives, points, awls, punches, picks, etc. were made either from whole long bones or from the splinters. Simple technique such as chiselling and grinding may have been practiced for the production of these tools. Tools such as copper chisels, parallel-sided stone blade and grinding stones may have been used in the manufacture of implements of bone and antler. Of course the Chalcolithic people may also have used a lot of wooden implements, which have not survived over such a long period.

\subsubsection{Stone}

Locally available stones were used for manufacturing objects such as rubbers, mullers, sling balls, hammers and saddle querns. By constant use the querns become hollow and curved and hence referred to as saddle querns. Grinding stones come in different shapes; round, oblong, rectangular and so on. Usually battering or use makes such as striation marks are found on the stone object used for hammering or grinding purposes. Stone balls or sling stones, which occur in large quantity, may have been used for hunting birds and small games. These objects of day-today use may have been manufactured locally at every site. None of the sites has yielded any evidence of the manufacture technique and therefore efforts will be made to reconstruct this technology.

\subsubsection{Ivory}

Some to the Chalcolithic sites have yielded small disc beads of ivory. Since only small quantity of beads were found, no effort has been made so far in reconstructing the technique used for manufacturing them. Ivory chunks may have been acquired from Gujarat and southern India and the production of beads may have been done locally. Copper wires and thin parallel-sided blades may have been used for cutting and beads may have been ground on the flat fine-grained sand stone.

\subsubsection{Textile}

The site of Balathal in Mewar region of Rajasthan has produced the physical remains of woven cloth, indicating the Chalcolithic people developed this art. Almost every Chalcolithic site has produced a large number of perforated discs, identified as spindle whorls. It is surmised that they were used in spinning thread, most probably of cotton. No evidence of cotton has been reported from any Chalcolithic site, but it was very much cultivated by the Harappans, who were contemporary to the Chalcolithic at some point. Traditional weaving looms are found in many parts of western India and they could provide ample evidence for reconstructing Chalcolithic technique. 
In addition to the above-mentioned craft there may also have existed technologies for making colour and medicine, evidence for which is yet to find.

\section{Concluding Remarks}

The Neolithic/Chalcolithic cultures that flourished almost all over South Asia, flourished mainly in the proximity of fertile arable land. Distinct phase of the Neolithic/Chalcolithic has not been identified in a number of countries of South Asia, including Sri Lanka, Bangladesh, Nepal, Bhutan and Burma. It is not sure whether this important phase is present or absent there. This phase bridges the gap between Stone Age and Early Historical age and provides an important clue to the missing link in the history of mankind in South Asia. Systematic research carried out in various parts of the subcontinent on the Chalcolithic phase has enabled reconstruction of social-economic and religious life of the people of that age. The presence of large-scale craft activities within some of the settlements is a clear indicator of the craft specialization and this is considered to be one of the characteristic features of the chiefdom society. The excavations at Inamgaon have produced ample evidence in support of a chief and the chiefdom social organization during the Chalcolithic times. The evidence for the presence of public buildings, strong hinterland trade, etc corroborate the presence of a chiefdom society during the Chalcolithic times. The traditions and technologies developed by the Neolithic/Chalcolithic community continued though ages and have survived even today. Rural India has preserved these traditions and it proves to be a very useful source for the reconstruction of various aspects of the Chalcolithic lifestyle, including technology.

\section{BIBLIOGRAPHY}

Agrawal, D. P. The Copper Bronze Age in India, Munshiram Manoharlal, Delhi, 1971
Agrawal, D. P. Ancient Metal Technology and Archaeology of South Asia: A pan-Asian perspective, Aryan Books International, Delhi, 2000

Agrawal, D.P. and Kharakwal, J.S. Bronze and Iron Ages in South Asia, Aryan Books International, Delhi, 2003.

Ansari, Z. D. and Dhavalikar, M. K. Excavations at Kayatha, Deccan College Postgraduate and Research Institute, Pune, 1975

Dasgupta, Debashree. Protohistoric and Early Historic Settlements in Rajsamand District, Southeast Rajasthan, Unpublished Ph.D. thesis of Deccan College, Pune, 2004

Dhavalikar, M.K. First Farmers of the Deccan, Ravish Publishers, Pune, 1988.

Dhavalikar, M. K., Sankalia, H. D. and Ansari, Z. D. Excavations at Inamgaon, Vol. I, Parts i and ii, Deccan College Post-Graduate and Research Institute, Pune, 1988

Dhavalikar, M.K., Shinde, V. and Atre, S. Excavations at Kaothe in Central Tapi Basin, Deccan College, PostGraduate and Research Institute, Pune, 1990

Jarrige, J.-F. Chronology of the Earliest Periods of the Greater Indus as Seen from Mehrgarh, Pakistan, South Asian Archaeology 1981, (B. Allchin Ed.), Cambridge University Press, Cambridge, 1984, pp. 21-28

Jarrige, Catherine., Jarrige, Jean-Francois., Meadow, Richard H. and Quivron, Gonzaque. Mehrgarh: Field reports 1974-1985, from Neolithic times to the Indus Civilization, Department of Culture and Tourism of Sindh, Pakistan, Department of Archaeology and Museums, French Ministry of Foreign Affairs, Karachi, 1995.

Kenoyer, J.M., Vidale M. and Bhan K. Contemporary Stone Bead Making in Khambat, India: Patterns of Craft Specialization and Organization of Production as Reflected in the Archaeological Record. World Archaeology, 2(1991): 13-85

Misra, V.N., Shinde, V.S., Mohanty, R.K. and Pandey, Lalit. Terracotta Bull Figurines from Marmi: A Chalcolithic Settlement in Chittorgarh District of Rajasthan, Man and Environment, 18.2(1993): 149-152

Sankalia, H.D. Pre and Protohistory of India and Pakisthan. Deccan College, Pune, 1974

Sankalia, H. D., Deo, S. B. and Ansari, Z. D. 1971 Chalcolithic Navdatoli: The excavations at Navdatoli 1957-59, Deccan College Postgraduate and Research 
Institute/Maharaja Sayajirao University Publication No. 2, Poona/Baroda, 1971

Shinde, Vasant. Farming in the Chalcolithic Deccan, Tools and Tillage, V:4, 1987, pp. 214-227.

Shinde, Vasant. New light on the origin, settlement system and decline of the Jorwe culture in the Deccan, India. South Asian Studies, 5, 1989

Shinde, Vasant. Craft specialization and social organization in Chalcolithic Deccan, Antiquity, 65.249(1991):796807

Shinde, Vasant. Experimentation in Archaeology: An Ethnographic Model, Archeologie Experimentale, Tome 1 - LE FEU: le metal, la ceramique, Societe des Autoroutes, Paris-Rhin-Rhone, 1991a, pp.22-29.

Shinde, Vasant. Two Unique Agricultural Implements from Walki: A Chalcolithic Farmstead in Western India. Tools and Tillage,VI: 4(1991b):210-215.

Shinde, Vasant. Pre-Harappan Padri Culture in Saurashtrathe Recent Discovery, South Asian Studies, 14(1998):1-10

Shinde, Vasant. The Origin and Development of the Chalcolithic in Central India, Indo-Pacific Prehistory Association Bulletin, 19(2000):125-36.

Shinde, Vasant. Emergence, Development and Spread of Agricultural Communities in South Asia, Origins of
Pottery and Agriculture, Y. Yasuda (Ed.), Roli Books and Lustre Press, Singapore, 2002, pp. 89-115.

Shinde, Vasant. Saurashtra and the Harappan sites of Padri and Kuntasi, Marg, 55.3(2004): 64-70

Shinde, Vasant., Deshpande, S. Sinha and Yasuda, Y. Human Response to Holocene Climate Changes- A Case Study of Western India Between $5^{\text {th }}$ to $3^{\text {rd }}$ Millennium BC, Monsoon and Civilization, (Y. Yasuda and V. Shinde Eds), Roli Books and Lustre Press, Singapore, 2004, pp. 383-406.

Shinde, Vasant, and G.L. Possehl. Excavations at Gilund 2001-2003: the Seal Impressions and other Finds, South Asian Archaeology 2003 (Ute Franke-Vogt and Hans Jochim Weisshaar Eds.), Linden Soft, Aachen, 2005

Sinha, Shweta. Study of Chalcolithic Social Organization in Central India With Special Reference to Balathal, Deccan College, Post-Graduate and Research Institute (Unpublished M.A. thesis), Pune, 1998

Sonawane, V.H. and P. Atithprasad. Harappan Culture and Gujarat, Man and Environment, 19.1-2(1994): 12939.

Tewari, Rakesh., Srivastava R.K., Singh K.K., Srivastava, K.S. and Singh, I.B. Preliminary Report of the Excavation at Lahuradeva, District Sant Kabir Nagar, U.P. 2001-2002: Wider Archaeological Implications, Pragdhara, 13 (2002-03): 37-68. 